\title{
Edge detection, depth estimation and 3D-inverse modelling of the Red Sea and Zagros gravity anomalies using the gravity data extracted from EGM2008 Geo-potential Model
}

\author{
Ali AMJADI ${ }^{1}$, Bahram AKASHE ${ }^{1, *}$, Mohammad ARIAMANESH ${ }^{2}$, \\ Mohsen POURKERMANI ${ }^{3}$ \\ ${ }^{1}$ Department of Geophysics, North Tehran Branch, Islamic Azad University, Tehran, Iran; \\ e-mail: amjadi.gp@gmail.com, akashebahram@gmail.com \\ ${ }^{2}$ Department of Geology, Payam Noor University, Tehran, Iran; \\ e-mail: aryamanesh.geo@gmail.com \\ ${ }^{3}$ Department of Geology, North Tehran Branch, Islamic Azad University, Tehran, Iran; \\ e-mail: Mohsen.Pourkermani@gmail.com
}

\begin{abstract}
Using geophysical methods and measuring physical properties of subsurface rocks are good solutions for investigating the subsurface structures and exploring underground buried resources (such as oil, gas, water, minerals, etc.). This research investigates the anomaly sources of Zagros and the Red Sea by using the derivative filters, regularized filters, analytic signal, local-phase filter, 3D-inverse modelling with the Li-Oldenburg method. For this purpose, these filters are first applied to artificial models to determine the capability of each of these filters, a comparison also will be made between edge detection filters and finally applied to the real gravity of Zagros and Red Sea regions (taken from the EGM2008 Global Model). The overall result is that the effective depth of the sources of gravity anomalies of the Red Sea is approximately $200 \mathrm{~km}$, and incoherently, up to a depth of $300 \mathrm{~km}$. The effective depth of the Zagros anomalies sources is also about $180 \mathrm{~km}$ and since then it has continued inconsistently up to $400 \mathrm{~km}$.
\end{abstract}

Key words: gravimetry, Li-Oldenburg inverse modelling, edge detection, analytic signal, local-phase filters, 3-D modelling

\section{Introduction}

The convergence of Arabian Plate and Central Iranian micro-continent is

*corresponding author: e-mail: akashebahram@gmail.com 
accompanied by numerous folding and fault systems and tectonic features created an index which is named Zagros fold- thrust belt. South East and West border of Arabian plate with Africa is the oceanic divergent boundary covered by the Gulf of Aden and the Red Sea, respectively.

Changes caused by various anomalies of the Earth's crust can lead to the formation of linear structures at the Earth's surface called the lineaments. Understanding these anomalies is used as an important factor in studying the tectonic status of each region. Some of these anomalies are buried by younger sediments and cannot be traced back to the surface; in this case geophysical methods can be used to identify hidden structures. One of these methods is the use of gravity data (Ariamanesh and Mahmoudpour, 2012).

Today, the effort to identify the buried structures and access to the subsurface resources has expanded widely, and geophysics is one of the tools to identify these structures. Using geophysical methods and measuring the physical properties of subsurface rocks are good solutions for investigating subsurface structures and exploring buried underground resources (such as oil, gas, water, minerals, etc.). To achieve this goal, using different edge and depth estimation filters, 2D and 3D modelling, are the most successful methods of interpreting geophysical data, which the result is a better understanding of subsurface structures such as source shape, amount of the depth, surface extent, deep stretching, etc. Determining these parameters has a direct and significant impact on future decisions, which can be effective in cost management. This research investigates the gravity anomaly sources of Zagros and the Red Sea by using the derivative filters, analytic signal, local-phase filter, 3D-inverse modelling with the Li-Oldenburg method.

There are two main purposes in this inversion method: in the first approach, the purpose of inversion is to determine the source geometry, and in the second approach, the purpose is to detect the density contrast of the mass in question with the surrounding environment. This method includes a multi-component objective function that is flexible enough to produce a variety of models and can be corrected for models that do not conform to geological structures. For this purpose, these filters are first applied to artificial models to determine the capability of each of these filters and finally applied to the real Zagros and Red Sea gravity data (taken from the EGM2008 Global Model). 


\section{Geologic and tectonic setting of the Zagros}

The Zagros mountain belt results from the closure of the Neotethys oceanic domain and the collision of the northern margin of the Arabian platform with the microplates of central Iran, accreted to the southern margin of Eurasia during the Mesozoic (e.g. Besse et al., 1998). The Zagros orogenic belt is bounded to the northwest by the East Anatolian left-lateral strike-slip fault (EAF) and to the southeast by the Oman Line (OL) (Falcon, 1969), which is here considered to be a transform fault inherited from the opening of Neo-Tethys (Alavi, 1994).

The fold and thrust belt on the Arabian Plate is a result of deformation of the Zagros Orogenic Belt (ZOB) passive margin sediments that have been caused by continental collision (Alavi, 1994; Ghasemi and Talbot, 2006; Horton et al., 2008; Allahyari et al., 2010; Saccani et al., 2013).

The Zagros were traditionally classified by distinctive lithological units and structural styles into four NW trending tectonometamorphic and magmatic belts (Fig. 1). These are bounded by defects on a regional scale such as the Main Zagros Thrust (MZT), High Zagros Fault (HZF) and Mountain Front Fault (MFF) (Del Chiaro et al., 2019; Agard et al., 2005 and references therein). The presence of negative isostatic anomaly near the Zagros main thrust (Synder and Barazangi, 1986) and seismic evidence with focal depths greater than $50 \mathrm{~km}$ in the ISC and USGS prove subduction of the Arabian plate beneath central Iran (Nowroozi, 1971).

Berberian (1995) described tectonic developments of this region as a platform phase in the Paleozoic, rifting in the Permian and Triassic, forming inactive continental margins (with seafloor spreading to the north-east) in the Jurassic and Early Cretaceous, subduction to the northeast and ophiolite and radiolite deposition in the late Cretaceous, and finally the continentalcontinental collision and shortening during the Neogene.

Today, their effects appear on or near the surface of the Earth as thrust faults. It can be said that the Zagros basement is about 25 to $50 \mathrm{~km}$ thickness (Gies et al., 1984).

Based on Dehghani and Makris (1984), under the main Zagros fault (high Zagros), gravity anomalies reach to a minimum (-230 mgal), and in this area, the Iranian crust thickness 50 to $55 \mathrm{~km}$ has the highest thickness, which is attributed to the compressive process associated with the opening of the Red Sea. 


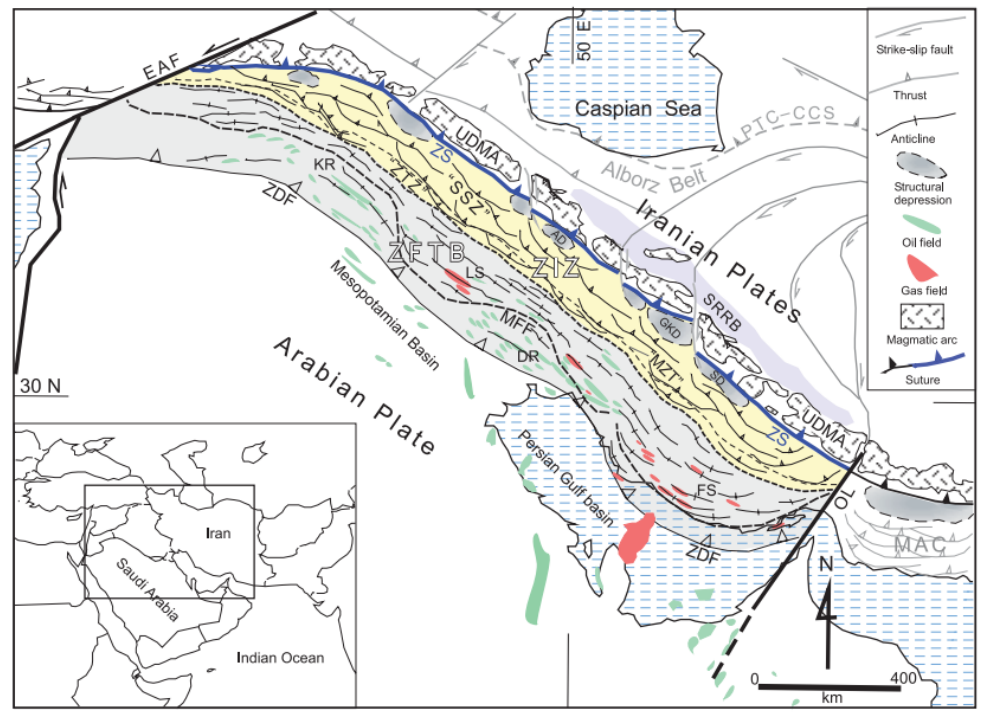

Fig. 1. Subdivisions of the Zagros orogenic belt. Abbreviations: AD - Arak depression; DR - Dezful recess; EAF - East Anatolian Fault; FS - Fars salient; GKD - Gav Khooni depression; KR - Karkuk recess; LS - Lorestan salient; MAC - Makran accretionary complex; MFF - "Mountain front flexure"; "MZT"- "Main Zagros Thrust"; OL - Oman Line; PTC-CCS - Paleo-Tethyan continent-continent collisional suture; SD - Sirjan depression; SRRB - Saveh-Rafsanjan retroforeland basin; "SSZ" - Sanandaj-Sirjan zone; "ZTZ" - Zagros thrust zone; UDMA - Urumieh-Dokhtar magmatic assemblage; ZDF Zagros deformational front; ZFTB - Zagros fold-thrust belt; ZIZ - Zagros imbricate zone; ZS - Zagros suture. Hydrocarbon fields of the region, oil in green and gas in red, are shown (Alavi, 2007).

\section{Geologic and Tectonic setting of the Red Sea}

The Red Sea, an enclosed body of water that lies between $30^{\circ} \mathrm{N}$ and $12^{\circ}$ $30^{\prime} \mathrm{N}$, is about $1,932 \mathrm{~km}$ long and $280 \mathrm{~km}$ in width (Morcos, 1970). The narrow southern Strait of Bab-al- Mandab (29 km in width) is the boundary between the Red Sea and the Gulf of Aden. The Red Sea is one of the youngest oceanic zones on earth and was created by slow seafloor spreading. Together with the Gulf of Aqaba-Dead Sea transform fault, it forms the western boundary of the Arabian plate, which is moving in a north-easterly direction. The plate is bounded by the Bitlis Suture and the Zagros fold belt and subduction zone to the north and north-east, and the Gulf of Aden 
spreading centre and Owen Fracture Zone to the south and southeast (Rasul and Stewart, 2015) (Fig. 2 modified after Stern and Johnson, 2010).

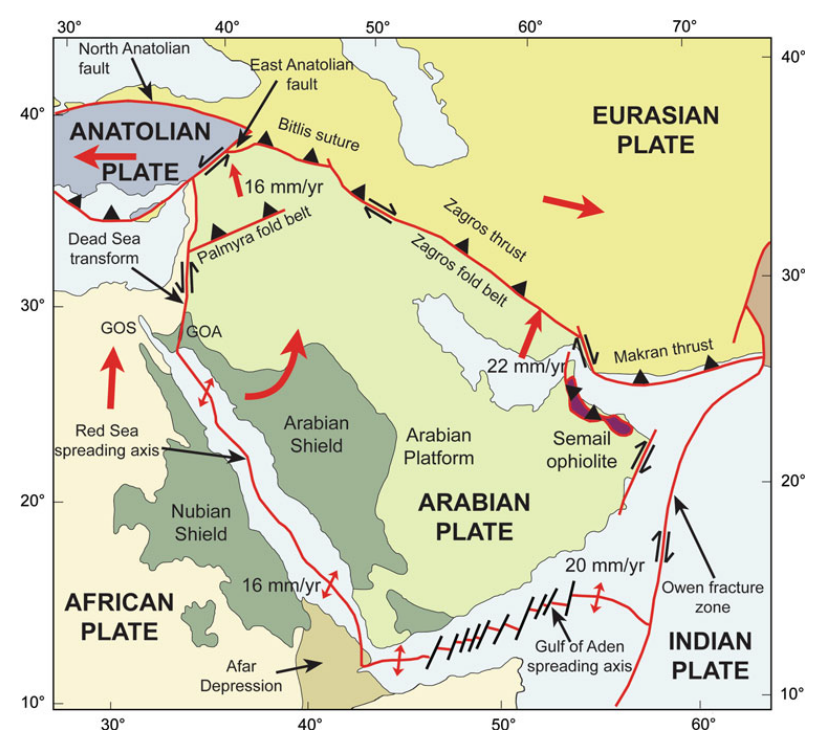

Fig. 2. Main tectonic features of the Arabian Peninsula and surrounding areas (modified after Stern and Johnson, 2010).

According to Swartz and Arden (1960), with the onset of Pliocene, marine sediments were deposited in the Red Sea due to the influx of water from the Indian Ocean into the Red Sea, meanwhile due to the uplift of the Suez Canal, the connection between the Mediterranean Sea and the Red Sea has been severed. The Red Sea Rift System is one of the world's largest active rift systems, which comprises a variety of rifting stages starting from initial faulting and advancing through several stages of continental rifting. It began about 30 million years ago, separating the western edge of the Arabian Plate from Africa (Camp and Roobol, 1992).

Sultan et al. (1993) have indicated that the Arabian and Nubian sections of the shield have remained as rigid plates during the Red Sea rifting, and the site of the present Red Sea has probably a zone of structural weakness in the late Precambrian, with the breakup and rifting controlled by pre-existing fault systems (Makris and Rihm 1991; Bosworth et al., 2005). A bathymetric and topographic map prepared from various sources is presented in Fig. 3 The sea is connected to the Arabian Sea and Indian Ocean via the 
Gulf of Aden in the south through the narrow Strait of Bab-al-Mandab, which has a minimum with of only $30 \mathrm{~km}$, where the main channel is about $310 \mathrm{~m}$ deep and $25 \mathrm{~km}$ wide at Perim Island (Morcos, 1970).

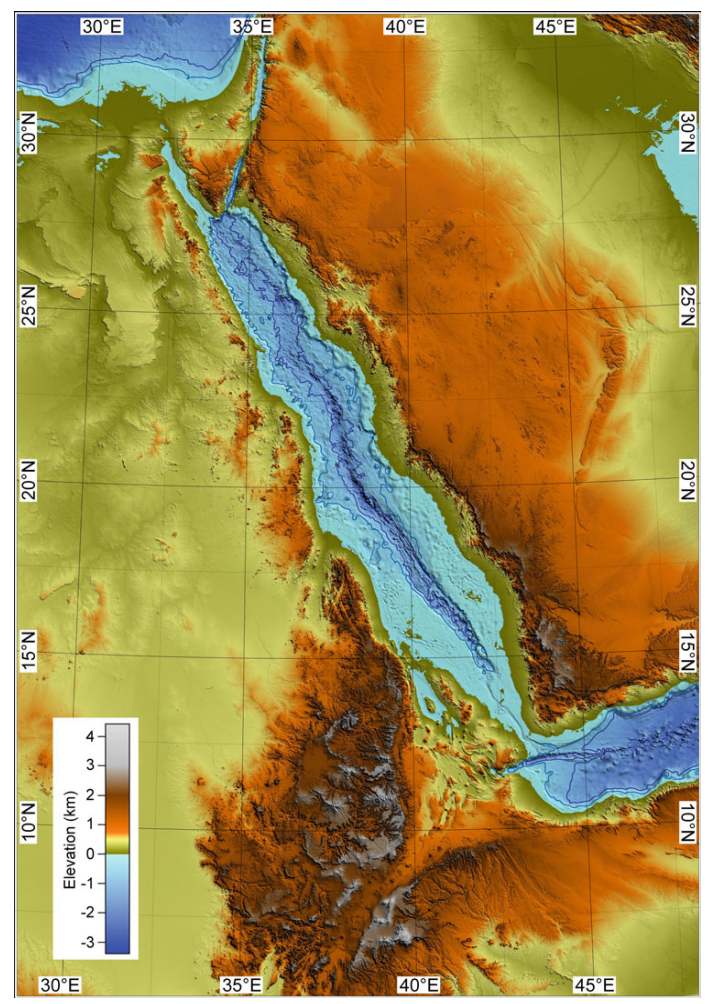

Fig. 3. Topography and bathymetric map. Bathymetric contours are at $500 \mathrm{~m}$ interval (Courtesy Marco Ligi).

The Red Sea has been opening since the Arabian plate broke away from the African plate about 24 million years ago (Bosworth et al., 2005). The rifting began with continental stretching and thinning and later progressed to sea-floor spreading. The rate of opening increases from about $7 \mathrm{~mm} /$ year in the northern Red Sea to roughly $16 \mathrm{~mm} /$ year in the south (ArRajehi et al., 2010; Reilinger et al., 2015). The present velocity of Arabia with respect to Eurasia increases from west to east along the Persian Gulf from 18 to $25 \mathrm{~mm} \mathrm{yr}^{-1}$, oriented about $\mathrm{N} 10^{\circ} \mathrm{E}$ (Madahizadeh et al., 2016; Sella et al., 2002, Walpersdorf et al., 2006). 


\section{Research methods}

\subsection{The basics of the gravity method and the filters used in this research}

Gravity surveying may be conducted on many scales, e.g., small scale prospecting, regional marine surveys and global satellite surveys (Foulger and Peirce, 200\%). The fundamental equation used for mathematical treatment of the data and results is Newton's Law of Gravitation:

$F=G \frac{m_{1} m_{2}}{r^{2}}$,

where $F=$ force, $m_{1}, m_{2}=$ mass, $r=$ separation distance, $G$ is the gravitational constant $\left(6.67 \times 10^{-11} \mathrm{~m}^{3} \mathrm{~kg}^{-1} \mathrm{~s}^{-2}\right)$.

The unit of measuring the acceleration of gravity is Gal $\left(1 \mathrm{gal}=1 \mathrm{~cm} \mathrm{~s}^{2}\right)$. But in practice, a smaller unit called milligal is usually used. Acceleration of gravity is not exactly the same everywhere, but is controlled by several factors such as latitude, elevation, mass, topography, and ultimately geology of the area. Therefore, in order to obtain geological information, corrections such as free-air correction, Bouger, latitude and topography must be applied to the measured initial values. Gravity studies are used extensively in the investigation of large- and medium-scale geological structures (Paterson and Reeves, 1985).

\subsection{Separation of regional and residual anomalies}

Potential field data map (gravity and magnetic field) is the sum of the effects of sources with different density and magnetism at different depths which in other words, the result of survey is related to all anomalies in the region. In these maps, the effects of bedrock are characterized by mild and linear changes (Doulati Ardejani, 2011) which are called regional anomalies, and more surface anomalies are called regional or residual anomalies. Regional anomalies have low frequency and long wavelength, while, residual anomalies have high frequency and short wavelength.

In gravimetric studies, in order to clarify more surface anomalies such as mines and faults, the effect of regional anomalies such as bedrock should be excluded from the data (Kolagari, 1992). 


\subsubsection{Surface Trend Remove filter}

One of the most flexible analytical techniques for determining the surface structures is the surface trend method (Hinze, 1990). In this method, the area field from observed values is approximated by the least squares method. This method is based on surface computation by mathematical method that best matches relate to the observed values (Agah et al., 2004).

\subsubsection{Edge Estimation Filters}

Potential field data has unique advantages in investigating lateral heterogeneity of geological masses, especially their edge position. When it comes to geological edge or boundaries, it mainly refers to the boundaries of faults, fractures, geological units, or rock units of varying density (Hadadian, 2011). Filtering the potential field data is a numerical processing that plays an important role in the modification and interpretation of magnetic and gravity data. Image processing can be mapped from image space to information space, which prepares the image for future analysis. This is done with a variety of filters, the main advantage of them is not the need to transfer data from one domain to another. Different types of filters specify distinct features (Danaei et al., 2011). Below we will review the most important Edge Detection filters.

\subsubsection{Derivative filters}

Derivative filters are one of the most widely used filters in interpreting potential field data and their role is to separate the residual anomalies from the regional ones and detect the edge. These filters include vertical derivative, total horizontal and directional filters (Verduzco et al., 2004). Vertical derivative magnitude at the edge place of the subsurface masses is zero and at the source is positive, and the horizontal derivative magnitude at the top of the subsurface mass edges is maximum and at the source is zero which this feature is used to detect the edge. Vertical derivative filter shows more obvious the edge and anomalies with increasing derivative order, but as it falls into the category of high pass filters, the available noise along with the surface anomalies are highlighted in the maps. For this reason, first and second order derivatives are more commonly used. As a solution of this noise 
damping is an adapted low-pass filtering of the computed derivatives - e.g. by means of the concept of Tikhonov regularization (Pašteka et al., 2009). As mentioned, since the horizontal derivative is maximal at the up of the edge of the subsurface masses, it is more applicable to gravity data and it is less used in magnetic data because of the dipole nature of the anomalies.

\subsubsection{Analytical signal filter}

The analytical signal or full gradient is defined as the combination of horizontal and vertical derivatives of the potential field data. The maximum amount of analytical signal is placed on the edges of the mass. One of the points of the method is that the horizontal and vertical derivatives of a potential function are Hilbert transforms of each other. The Hilbert transform does not change the amplitude of the input function but changes its phase to 90 degrees. Consequently, Hilbert transforms of the horizontal derivative of the potential field data presents the vertical derivative of the data (Nabighian, 1972).

\subsubsection{Local-phase filter}

\subsection{Tilt Angle filter}

Tilt Angle filter is one of the local phase filters which is based on the ratio of the gravity field derivatives and examines the phase (angular) variations of the potential field derivatives. This filter is effective in balancing the amplitude of deep anomalies to surface anomalies and is not sensitive to the depth. In other words, tilt angle filter separates deep and shallow sources equally (Miller and Singh, 1994). Since the tilt angle filter has a direct relation with the vertical and a verse relation with the horizontal derivative, so at the edge of the anomaly, the tilt angle value is zero (Cooper and Cowan, 2006).

\subsection{Hyperbolic Tilt Angle Filter}

If the actual part of the hyperbolic tangent function is used instead of the tangent function in the calculation of the tilt angle, the edge of the 
subsurface masses will be more extremely prominent. The minimum value of this filter will be located just above the edge of the mass. One of the most important advantages of this filter is it's insensitivity to existing noise (Cooper and Cowan, 2006).

\subsubsection{Regularized Derivative Filter}

Since vertical derivative filters are high pass filters, noises filed will be sharper. One way to stabilize higher derivative evaluation is the utilization of the Tikhonov regularization (Pašteka et al., 2009). In this method, regularized derivative filter minimized or optimized with the usage of classical calculations in the Fourier domain and optimum regularization coefficient calculated from C-norm function (Pašteka et al., 2009). Now figures of regularized derivative are presented.

\subsubsection{Upward Continuation Filter}

Upward continuation method of potential field data is widely used in geophysics. For example, this method is used to enhance and reveal deeper resource responses in places where shallow resources are also available. In this method, the potential field data from a datum level is mathematically imaged on the level surfaces above the main datum level. Thus, effects of the removed surface tracks and the effects of deep structures are clearly identified. In fact, with this method, anomalies with shorter wavelength removed and thus it reduces noise, and acts similar to a low-pass filter (Reynolds, $1977)$.

\subsubsection{An introduction to Modelling}

After performing geophysical measurements, correction, data processing, and separation of local anomalies from area anomalies, the important stage is interpretation. All geological, geophysical and other related data must be used in the interpretation process to obtain the best possible interpretation. The methods of geophysical data interpretation can be divided into three main groups, each approaching the purpose with logical but different processes: 


\subsubsection{Enhancing and data depiction}

In this method, none of the model parameters are calculated, but the anomaly is processed and depicted in a way that makes some of the features of the source more salient and the overall interpretation easier. All of these methods can be used as complementary tools in modelling (Blakely, 1996). For example, a variety of edge detection methods fall into this category of interpretation of geophysical data.

\subsubsection{Forward modelling}

In the Forward modelling, based on existing geological observations or geophysical studies, an initial model for the anomaly is considered, the gravity effect of this model is calculated and compared with the observed gravity anomaly. In case of insufficient fitness, the interpreter modifies the parameters of the model so as to obtain the best fit between the effect of model gravity and the observed gravity anomaly. In fact, in this method, the characteristics of the model are determined by trial and error method (Ebrahimzadeh Ardestani, 2010).

\subsubsection{Inverse modelling}

In this method, the characteristics of anomaly source are calculated automatically or semi-automatically and using observed data. One of the most advanced methods of 3D inverse modelling is Li- Oldenburg's theory developed at British Colombia University in Canada and they used it as the basis of Grav3D software (Jafarzadeh, 2015). The main mathematical explanation of this theory is beyond the scope of this paper and for further reading, you can refer to more useful references (Williams, 2008; Philips, 2001; Li and Oldenburg, 1998).

\subsection{Artificial data}

To optimally use and apply a method, filter or algorithm and analyze the results in various geophysical methods, first, its application to artificial data with noise is examined. This method is used to check real data in an area, 
based on the degree of concordance with the main response (Jafarzadeh, 2015).

In this section, to investigate the performance of different filters such as edge detection and inversion by Li-Oldenburg method in reconstructing multiple anomalies and with different depths, an artificial model consisting of two rectangular cubes in the north-west and south-east, with 15 up and 40 down $\mathrm{m}$ depth, and a rectangular cube in the northeast with 25 up and 50 down $\mathrm{m}$ depth is used which the density contrast of cubes with the surrounding environment is $2 \mathrm{~g} / \mathrm{cm}^{3}$. This artificial model was built using 216,000 cells of equal width and length of 5 metres and elevation of 2.5 metres (Fig. 4). For inversion, the gravity effect of these bodies was calculated on a regular square grid at $5 \mathrm{~m}$ intervals, yielding 3600 data points. To make the data appear realistic, Gaussian noise was added to the data by $2 \%$ (Jafarzadeh, 2015).

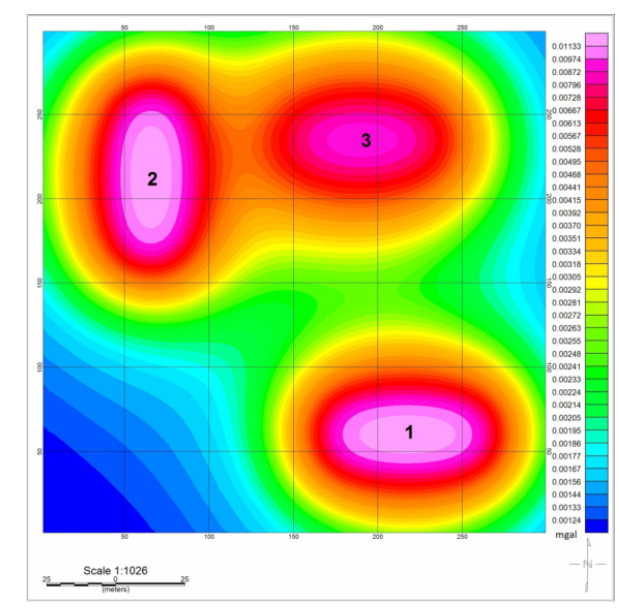

Fig. 4. Residual anomaly map derived from artificial model.

The results of applying the edge detection filters are presented below. All the numerical derivatives, entering into these derivative filters where calculated by means of the concept of regularized derivatives (Pašteka et al., 2009).

As can be seen in Figs. 8 and 6, the stretching of the anomalies is greater than in Fig. 4 and closer to the original form. Also in Fig. 7 that shows the horizontal derivative filter (the forming angle with the positive side of the 


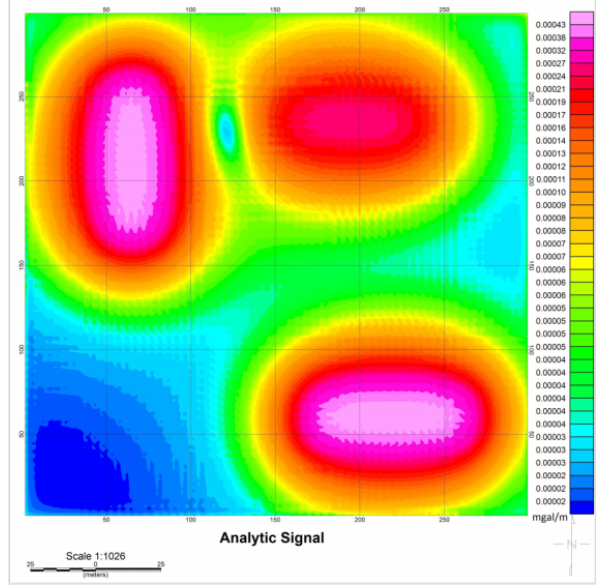

Fig. 5. Analytical signal filter.

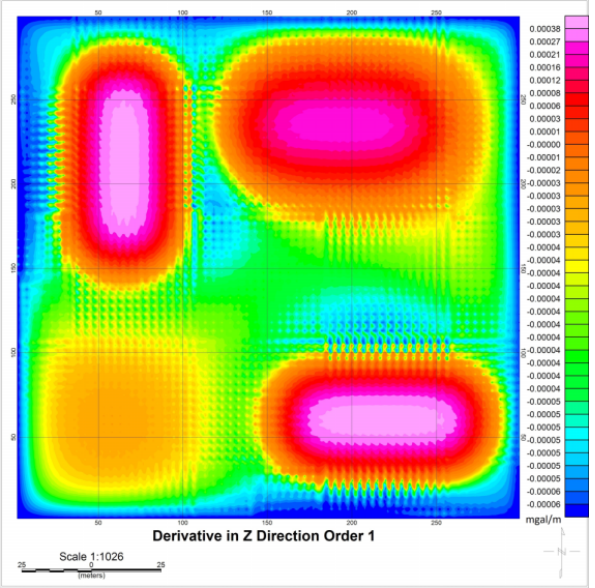

Fig. 6. Vertical derivative filter.

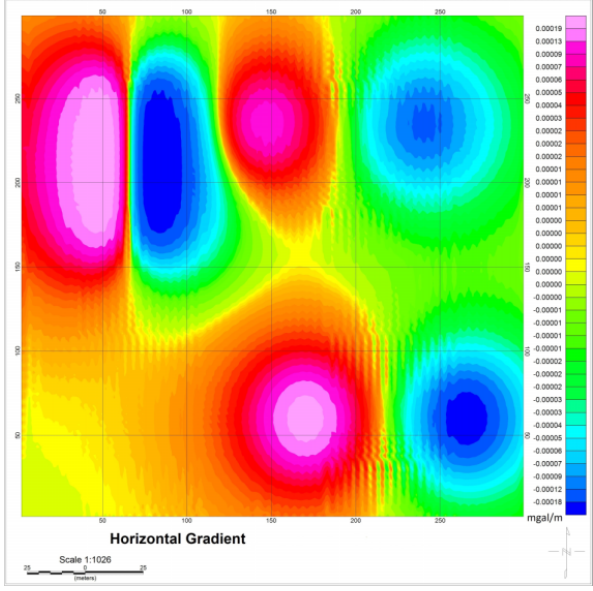

Fig. 7. Horizontal derivative filter.

$\mathrm{X}$ axis is zero), the anomalies stretch along the $\mathrm{Y}$ axis and receive a dipole character. It is important to note that in this filter, if the dipoles are closer to each other and stretch in a particular direction (not symmetrical), the main anomaly stretches in the same particular direction, but if the dipoles are symmetric and not close together, they stretch perpendicular to the angle with the X-axis. Figs. 8 and 9, which represent the tilt angles and the hyperbolic tilt angles, respectively, are well able to detect the edge of the 


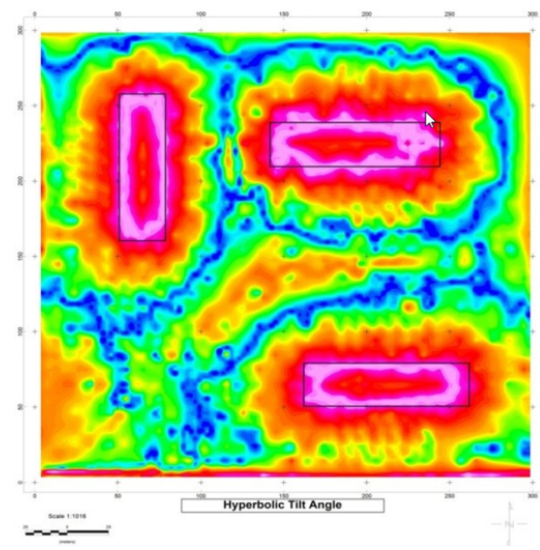

Fig. 8. Hyperbolic tilt angle filter.

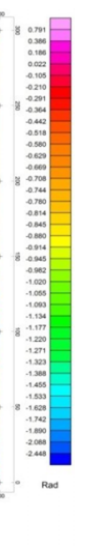

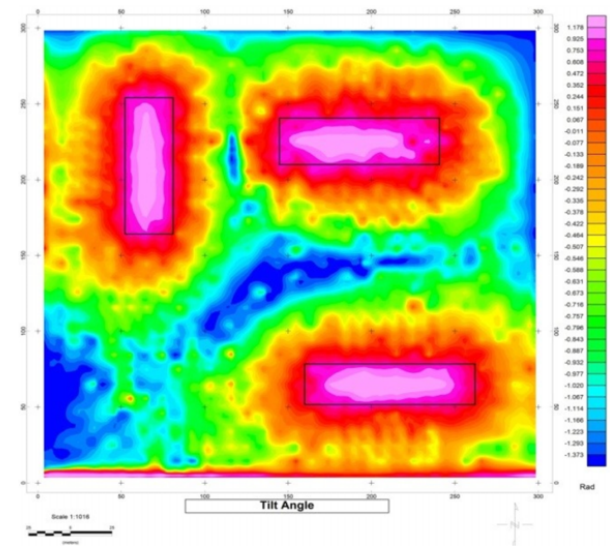

Fig. 9. Tilt angle filter.

anomalies. Now figures of regularized derivative are presented.

In the following, the validity of Li-Oldenburg 3-D inversion modelling method on artificial data is discussed. One of the advantages of this modelling method is that it is possible to include a variety of complementary area information (such as geological information, drilling, etc.) into the modelling so that the final model obtained is as close to reality as possible. Fig. 13 is a 3D view of the artificial model used, and Figs. 14 and 15 are im-

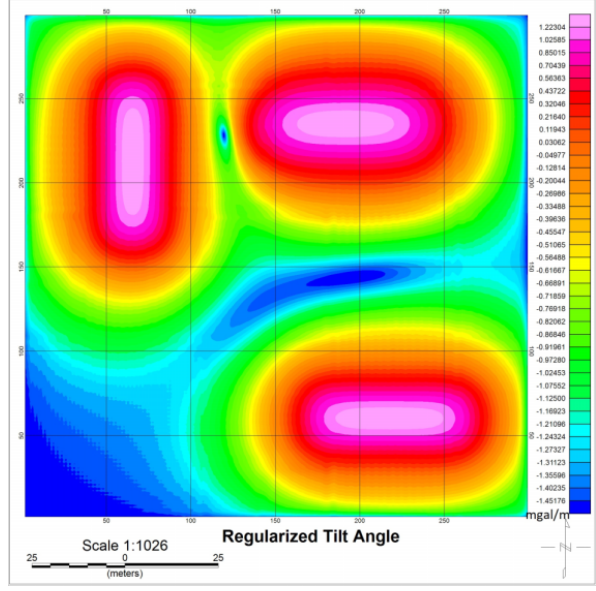

Fig. 10. Regularized tilt angle filter.

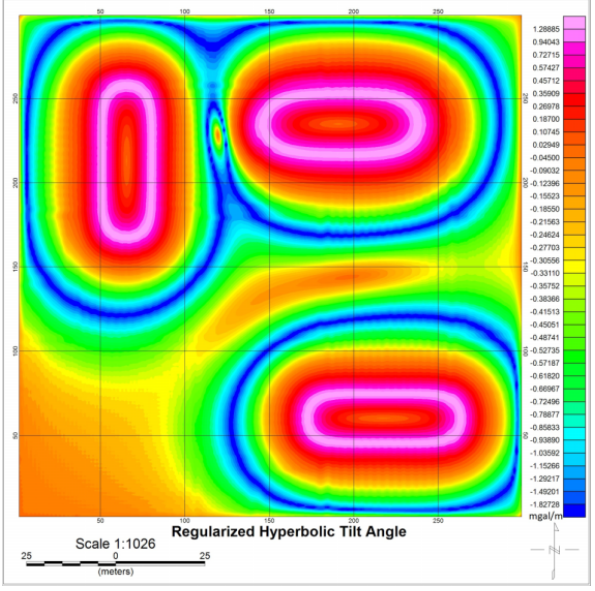

Fig. 11. Regularized hyperbolic tilt angle. 


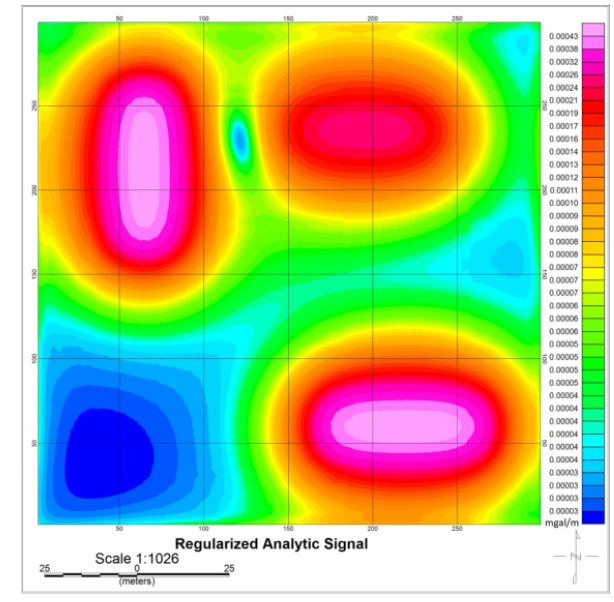

Fig. 12. Regularized analytical signal filter.
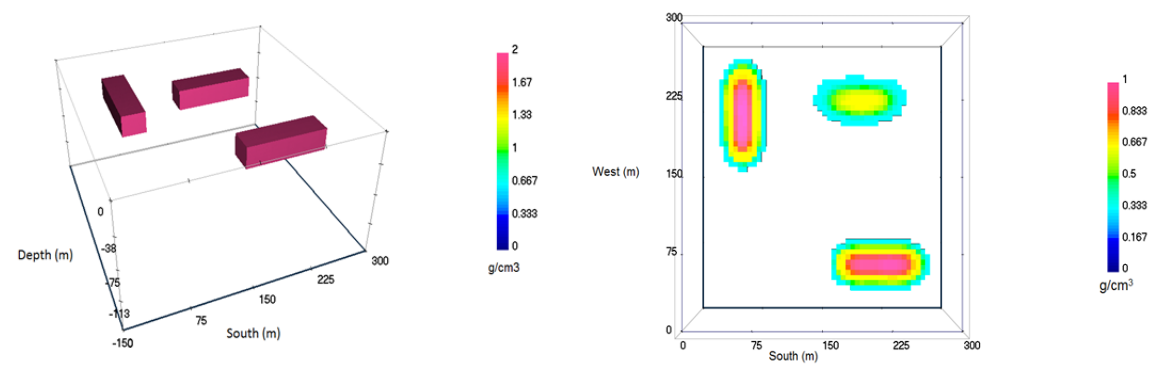

Fig. 13. 3D view of the compound arti- Fig. 14. Top view of artificial model inversion. ficial model.

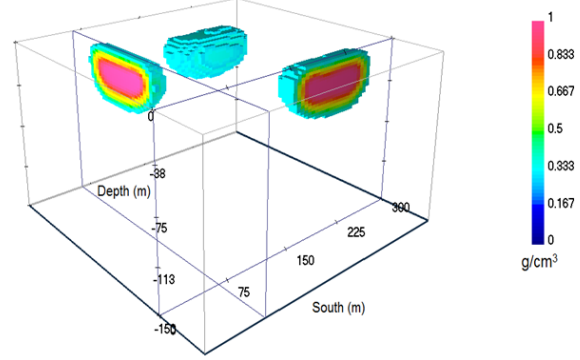

Fig. 15. Another view of artificial model inversion. 
ages of the 3-D inversion that provide acceptable agreement with the original artificial model. Comparing figures of regularized derivative (Figs. 10-12) and simple mode of them, it is clear that regularized derivative mode has a much better performance and their noise significantly reduced.

\subsection{Real data}

\subsubsection{Edge Detection of Zagros and the Red Sea Anomaly}

The gravimetry data output (complete Bouger anomaly) obtained from the EGM2008 satellite for the Zagros and Red Sea regions is as follows (Figs. 16 and 17):

As can be seen from the above figures, the trend dominating these two regions is the lineaments in the form of maximum and minimum anomalies together from northwest to southeast. As previously described, gravimetric data maps are the result of regional and residual anomalies. To investigate and highlight the surface structures, we remove the effects of the regional anomalies whose results are shown in Figs. 18 and 19, using the Trend Remove filter. It is noteworthy that this filter and future filters were implemented in the Oasis Montaj software environment owned by Geosoft Company. Comparing Figs. 16 with 18 and 17 with 19, we find that the intense of the anomalies are increased, such as the central anomaly of Fig. 18 and the end of it in Fig. 19 (southeast) became more salient.

The complete Bouger maps or the surface trend remove map cannot be used properly to detect the edge or boundary of Zagros or the Red Sea anomalies. Edge detection filters are used to do this. All of these filters are applied on the complete trend removed Bouger map. Also here, we have used the computed numerical derivatives by means of the Tikhonov concept of regularization (Pašteka et al., 2009). It is important to note that the reason for applying several edge detection filters is to get the result closer to reality.

\subsubsection{Edge detection of Zagros anomalies}

Figs. 20, 21 and 22 are the maps obtained by applying Horizontal Gradient, Analytical Signal, and Derivative in Z direction Order 1 filters, respectively, to Zagros data. As is clear from the figures below, the boundaries of the 


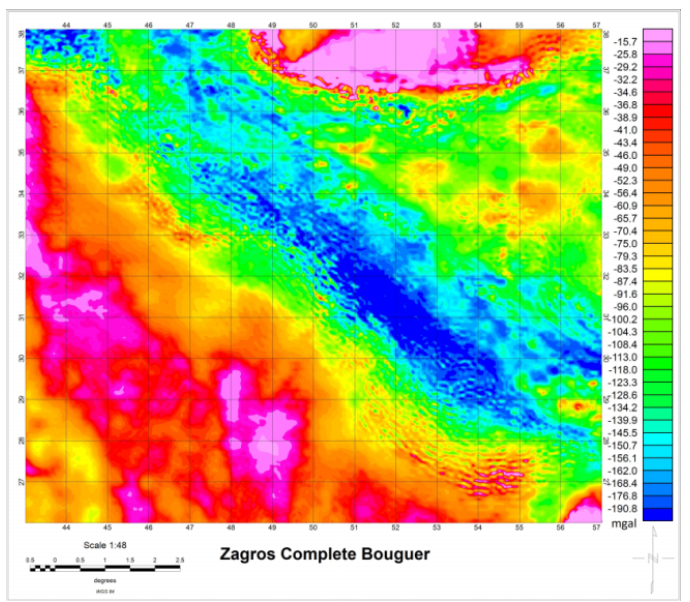

Fig. 16. Complete Bouguer anomaly map of the Zagros.

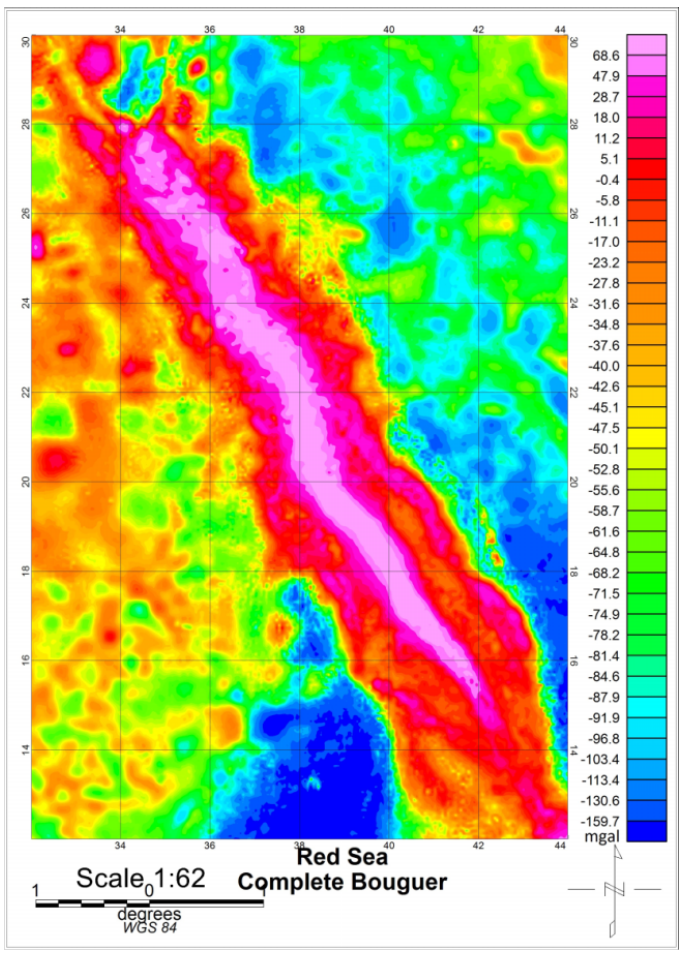

Fig. 17. Complete Bouguer anomaly map of the Red Sea. 


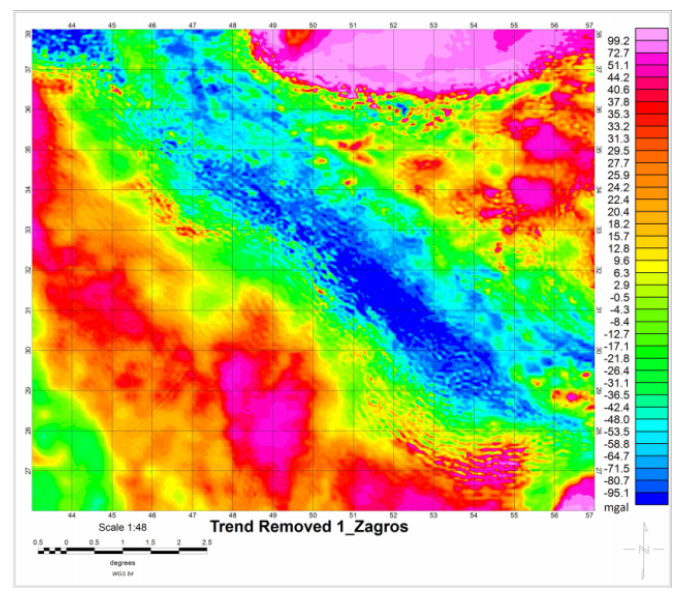

Fig. 18. Removing the first-order trend map of the Zagros.

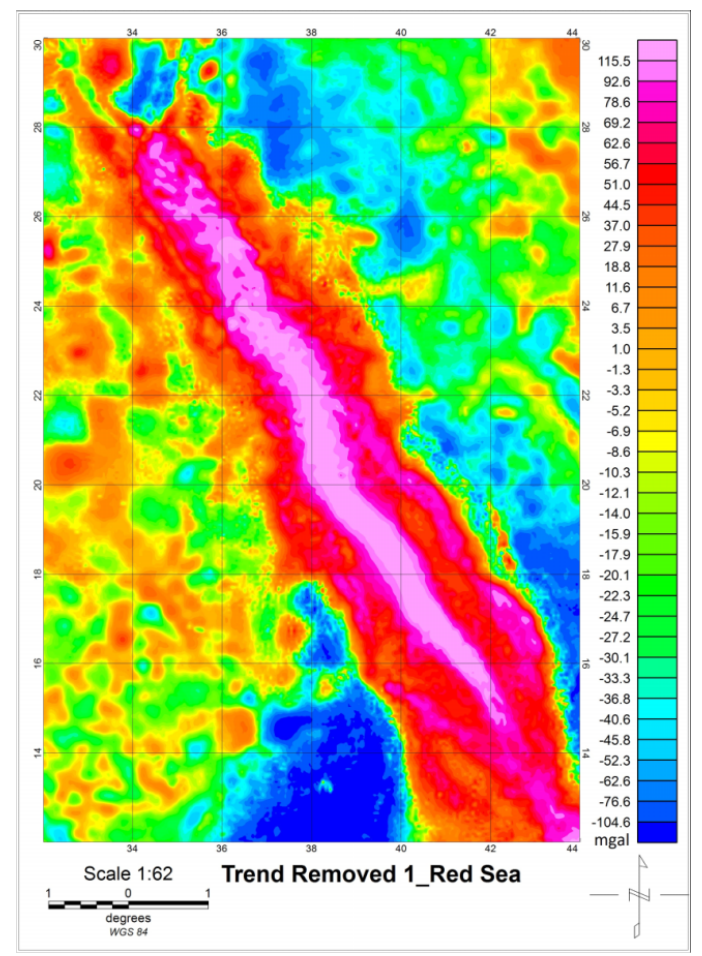

Fig. 19. Removing the first-order trend map of the Red Sea. 


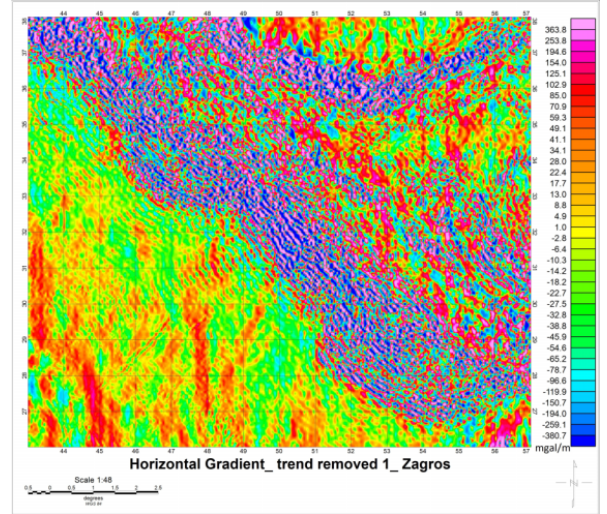

Fig. 20. Horizontal gradient filter map of the Zagros.

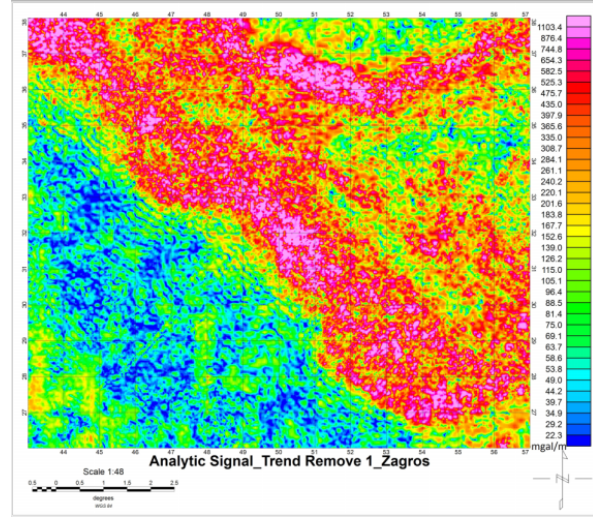

Fig. 21. Analytical signal filter map of the Zagros.

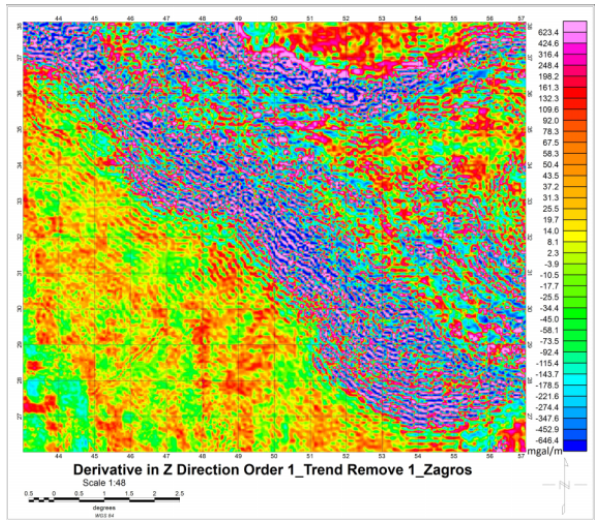

Fig. 22. First-order vertical derivative filter map of the Zagros.

maximum and minimum anomalies have been well characterized, and the reason for the colour change or anomalies resulting from the application of the analytical signal filter is its 90 degree phase change due to the nature of the filter (already explained). In these figures, the anomalies extend from northwest to southeast with indentations and densities.

Potensoft software including MATLAB codes was also used for further check and validate these filters (Arısoy and Dikmen, 2011) and the Tilt Angle and Hyperbolic Tilt Angle filters were applied to the data using this software, shown in Figs. 23 and 24.

As mentioned earlier, these filters highlight the edge of all relatively deep 
Amjadi A. et al.: Edge detection, depth estimation and 3D-inverse modelling ... (1-32)
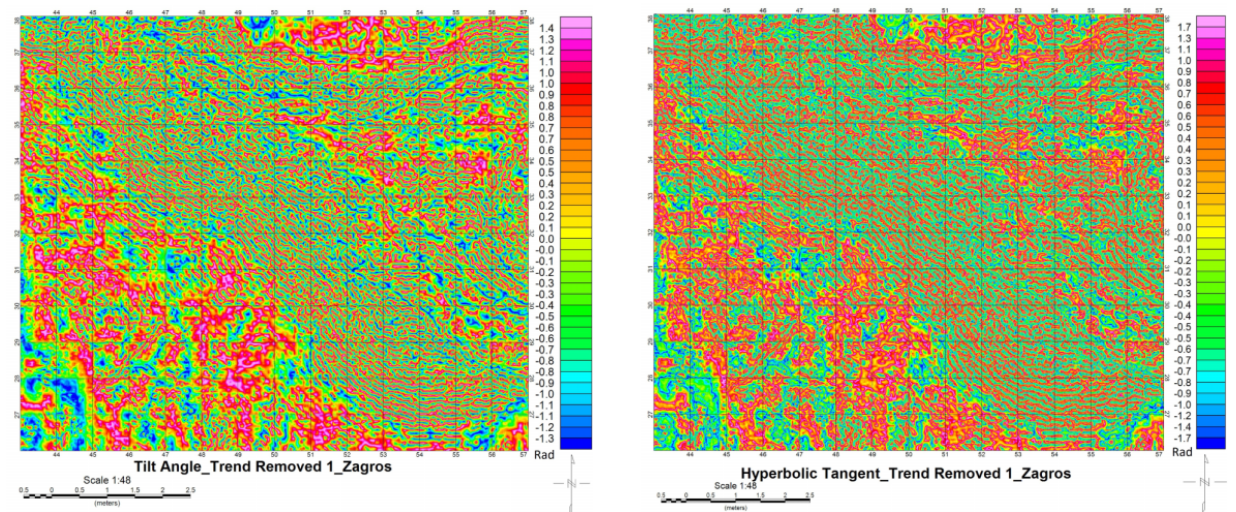

Fig. 23. Tilt angle filter map of the Zagros. Fig. 24. Hyperbolic Tilt angle filter map of the Zagros.

and near surface anomalies because they lack depth sensitivity, as a result, the resulting maps are more crowded than previous filters; however, one can still see the structural difference of Zagros anomalies with the region containing Zagros. The conclusion is that these filters also confirm the results of the rest of the filters. Summary of the results of the above filters are shown in Fig. 25 and the anomalies continuation is marked with a black line. Comparing the results of these filters with this map gives more reliable results that will complement the geological data. Now we are testing regularized derivative filters (Figs. 26-30).

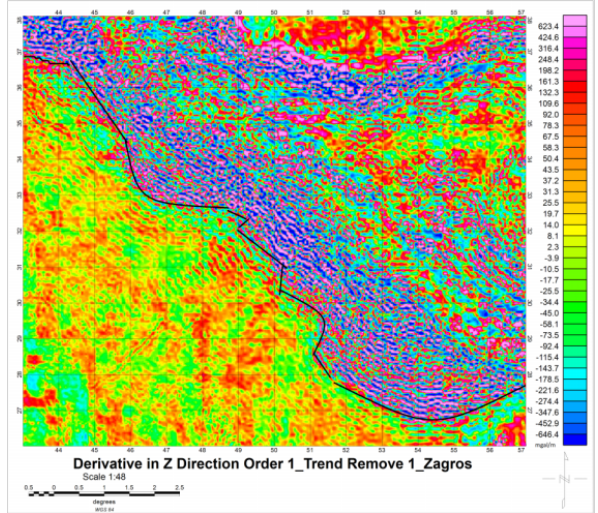

Fig. 25. Edge detection and continuation of Zagros anomalies with the black line.

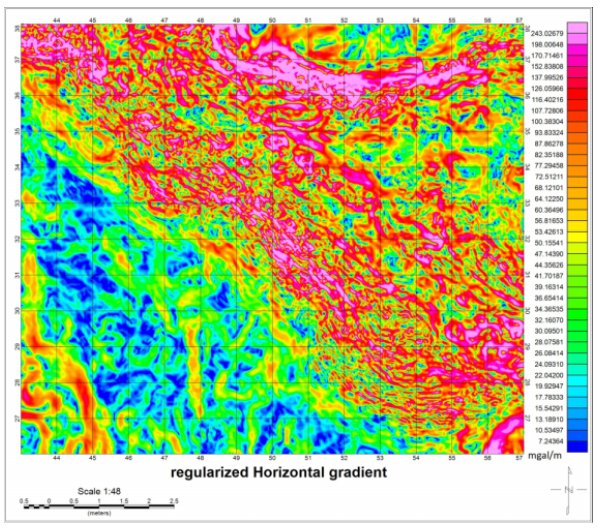

Fig. 26. Regularized horizontal gradient filter map of the Zagros. 


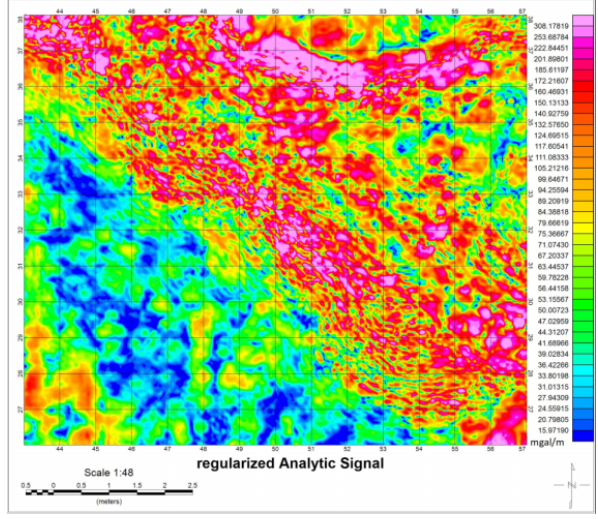

Fig. 27. Regularized analytic signal filter map of the Zagros.

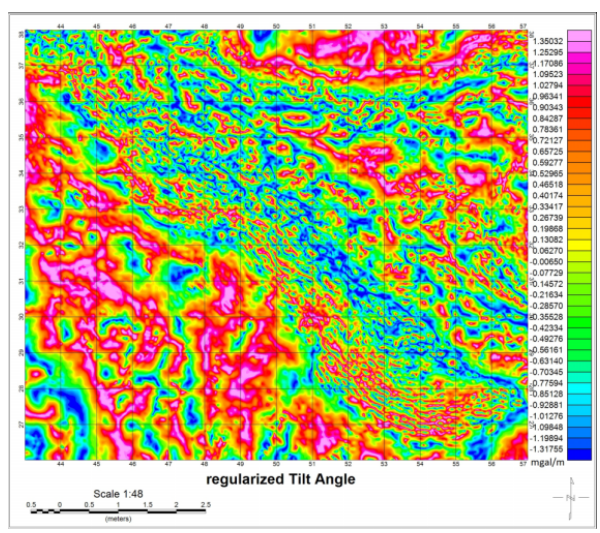

Fig. 29. Regularized tilt angle filter map of Fig. 30. Regularized hyperbolic tilt angle the Zagros.

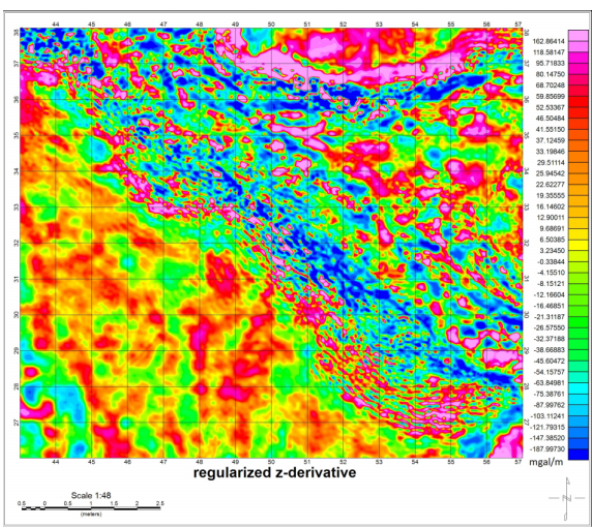

Fig. 28. Regularized first-order vertical derivative filter map of the Zagros.

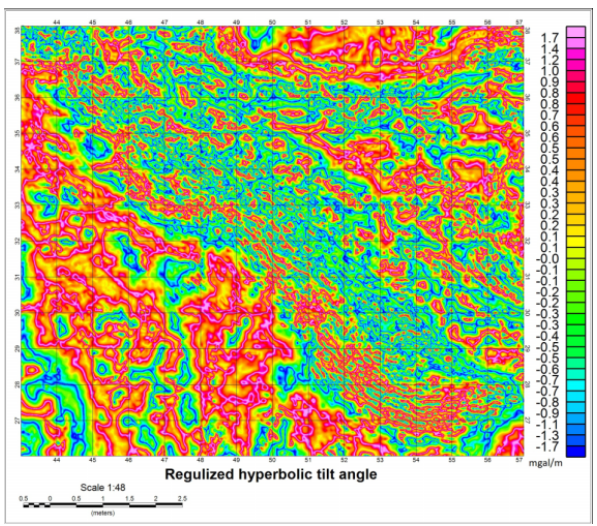
map of the Zagros.

As we have seen in these figures, regularized derivative filter has a much better performance.

\subsubsection{Edge detection of the Red Sea gravity anomalies}

Figs. 31, 32, and 33, respectively, show the maps obtained by applying horizontal gradient filters, analytical signal and first-order vertical derivative on the Red Sea data. In these figures, the edge of maximum and minimum 
Amjadi A. et al.: Edge detection, depth estimation and 3D-inverse modelling... (1-32)

anomalies is also obvious, but more complex than the Zagros region. Figs. 34 and 35 are the results of applying tilt angle and hyperbolic tilt angles to the data. These filters also confirm previous results.

Figures 34 and 35 are the result of applying tilt angle and hyperbolic tilt angle filters to the data.

Summary of the results of the above filters are shown in Fig. 36 and the anomalies continuation is marked the black line.

Given that the data used are derived from gravimetric satellite, it is obvious that the satellite data is much less sensitive to ground-based data survey, so it cannot be expected to make all the anomalies visible. If more accurate gravimetric data (such as ground-based survey) are available, gravimetric method is a great way to identify small and large anomalies in the area. The overall result of the study of the two zones is that the Zagros and Red Sea gravity anomalies have one continuity (from northwest to southeast) with this difference which there is a greater overall slope in the Red Sea.

In the following the results of the implementing regularized derivative filters are presented and by comparing the Figs. 37 to 41 with the Figs. 32 to 36 again it is completely clear that regularized derivative filters have much better performance.

\subsection{Inversion modelling of Zagros and the Red Sea gravity anomalies}

Before proceeding further, it is important to note that since the EGM2008 satellite data output is in latitude and longitude, the UTM coordinate points need to be used in order to use the upward continuation filter. By converting the coordinates, the Zagros and Red Sea anomalies each fall into three zones. Red Sea anomalies are located in zones 36, 37 and 38 and Zagros anomalies are located in zones 38, 39 and 40 respectively. The most extensive zones (zones 37 for Red Sea and 39 for Zagros) were used to apply upward continuation filter and 3D modelling.

\subsubsection{Red Sea gravity anomalies}

This section presents the results of the inversion of the gravimetric data of the Red Sea anomalies using Grav3D software. The results of 3-D inversion 


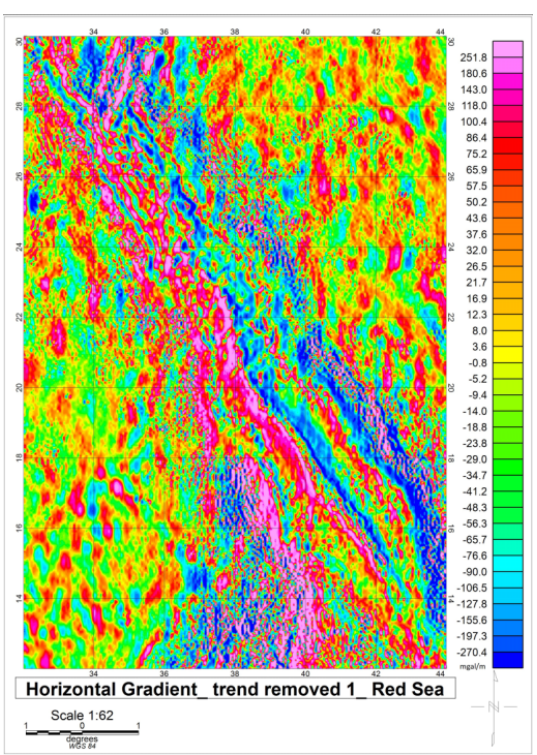

Fig. 31. Horizontal gradient filter map of the Red Sea.

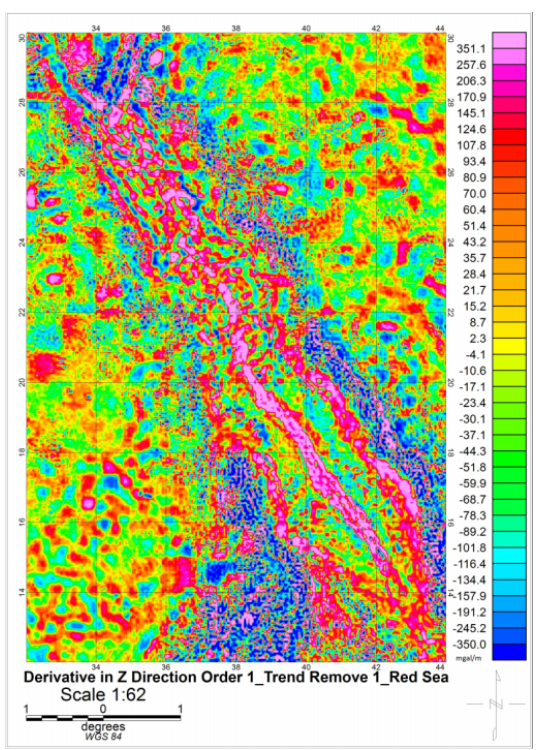

Fig. 33. First-order vertical derivative filter Fig. 34. Tilt angle filter map of the Red map of the Red Sea.

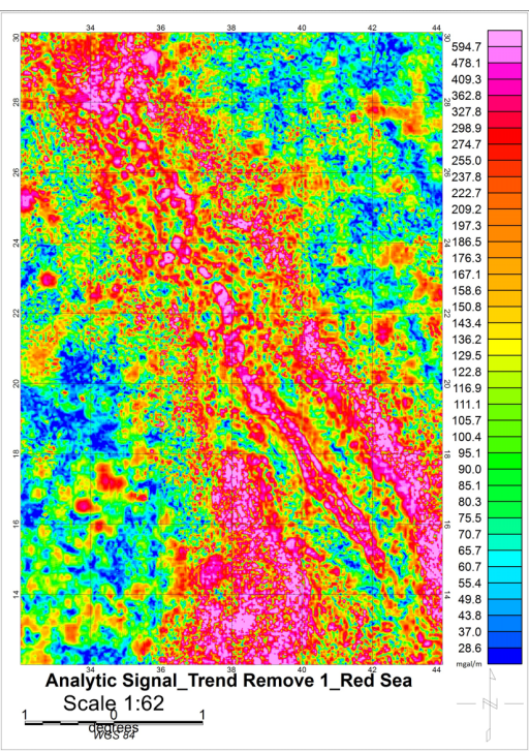

Fig. 32. The Analytical signal filter map of the Red Sea.

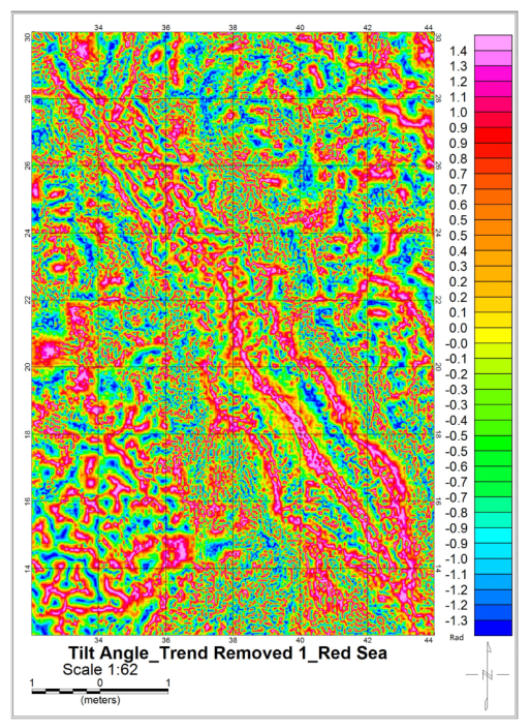

Sea. 


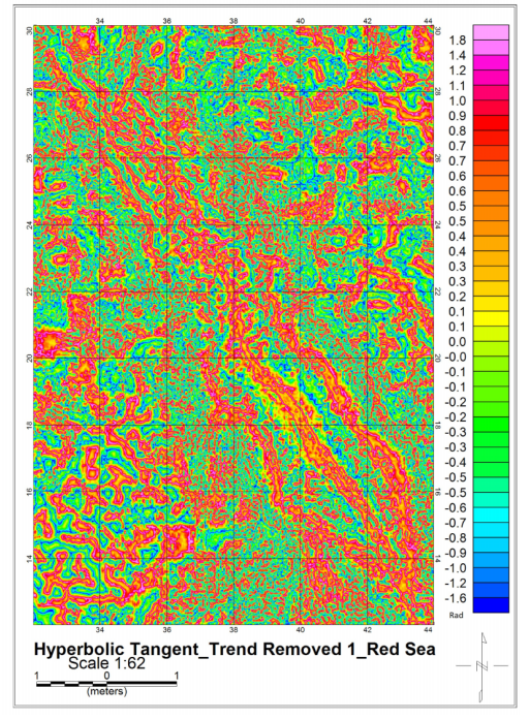

Fig. 35. Hyperbolic tilt angle filter map of Fig. 36. Edge detection and continuation of the Red Sea.

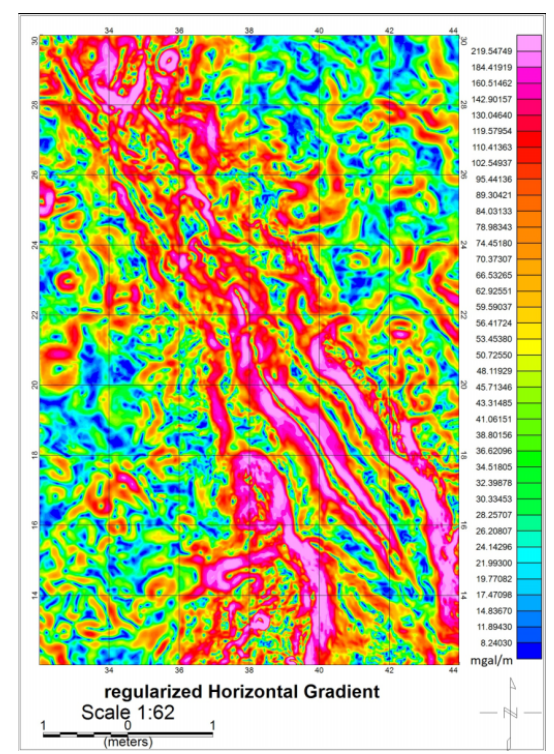

Fig. 37. Regularized horizontal gradient fil- Fig. 38. Regularized Analytical signal filter ter map of Red Sea.

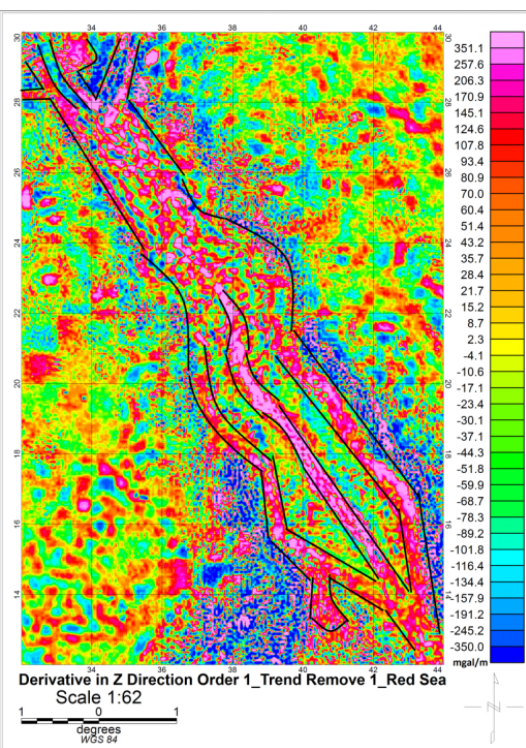

Red Sea anomalies with black line.

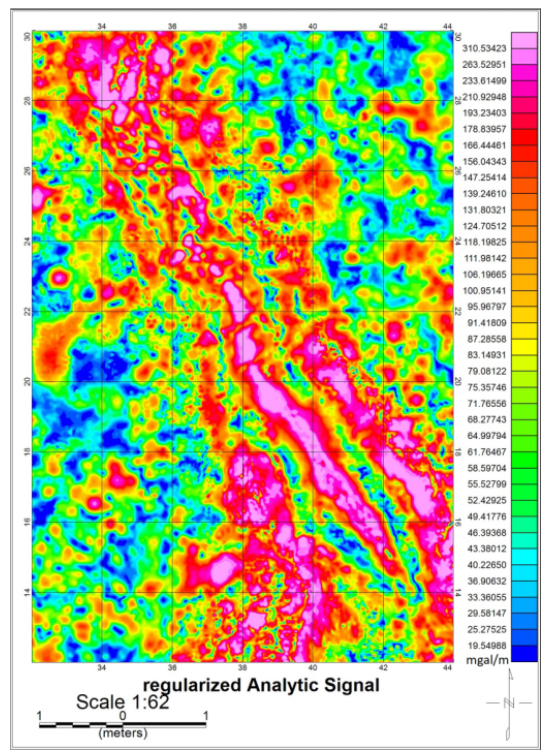

map of Red Sea. 

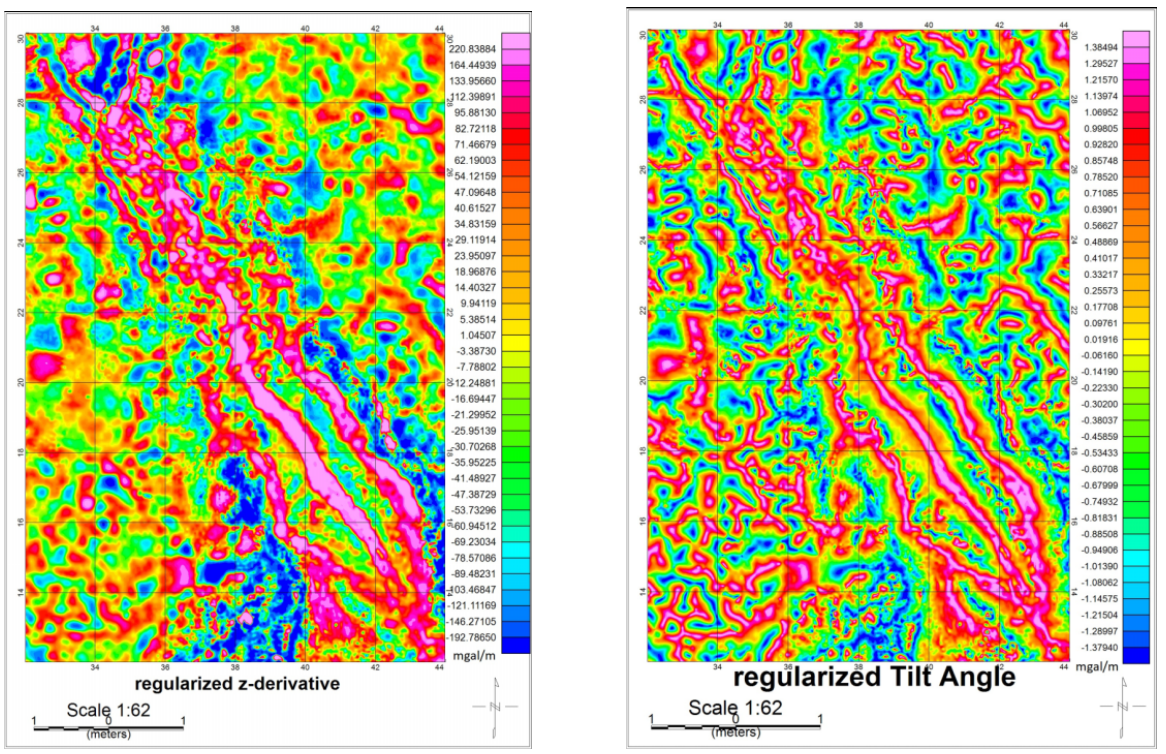

Fig. 39. Regularized vertical derivative fil- Fig. 40. Regularized tilt angle filter map of ter map of the Red Sea. the Red Sea.

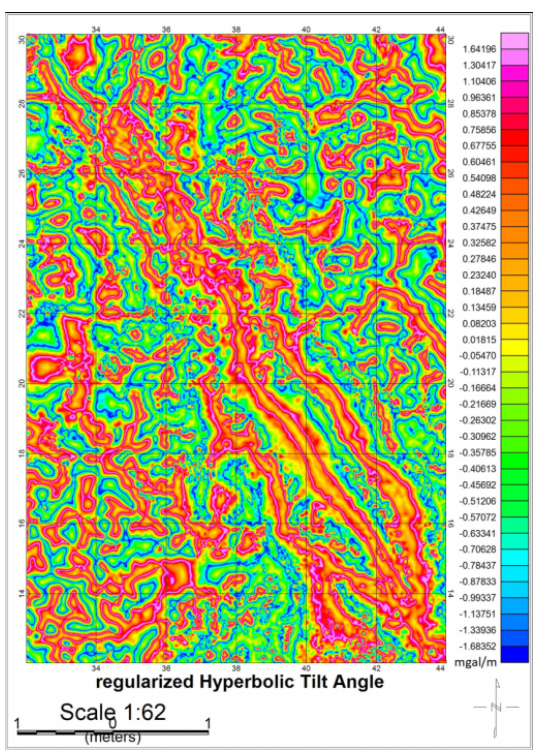

Fig. 41. Regularized Hyperbolic tilt angle filter map of the Red Sea. 
are shown in Figs. 42 and 43, in which the main and secondary directions of the anomalies are well reconstructed. Fig. 44 shows the effective depth of the anomalies at $200 \mathrm{~km}$ from the surface and Fig. 45 confirms the anomaly ends at the $300 \mathrm{~km}$. According to Fig. 36, the anomalous two-branch depth is lower than its original branch because these two branches continue to a depth of $100 \mathrm{~km}$ and then disappear (hence extending to a depth of $100 \mathrm{~km}$ ).

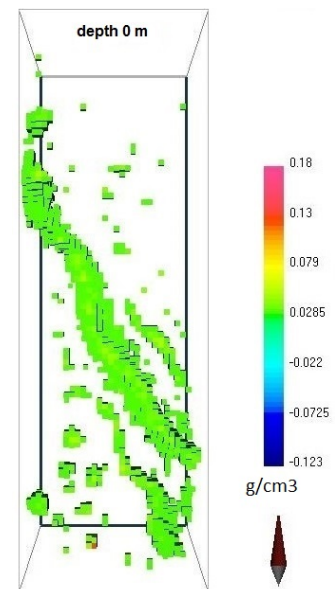

Fig. 42. Inversion of the Red Sea anomalies (top view).

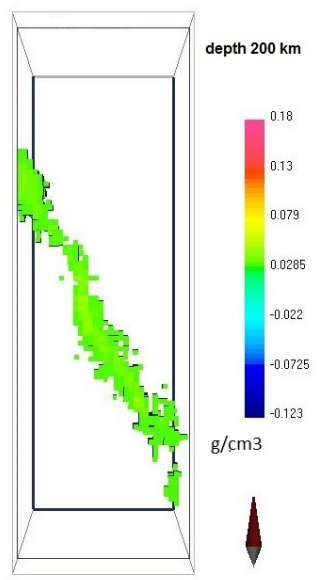

Fig. 44. Inversion at $200 \mathrm{~km}$ depth.

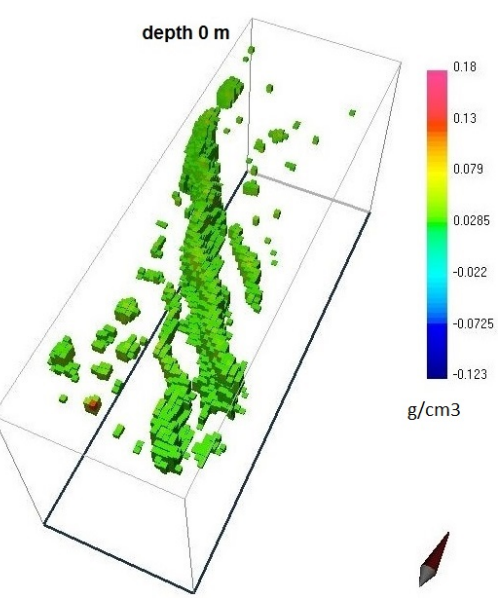

Fig. 43. Another view of Fig. 42.

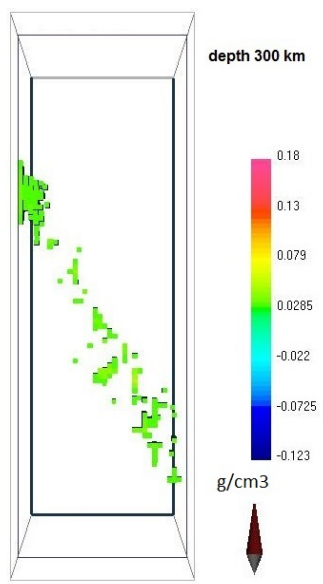

Fig. 45. Inversion at $300 \mathrm{~km}$ depth. 


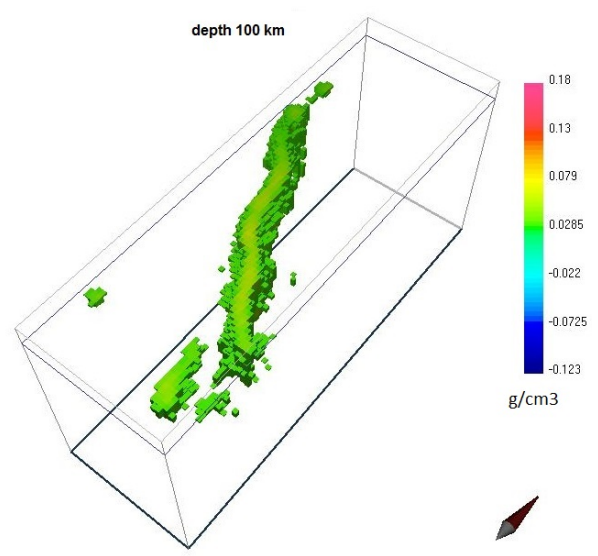

Fig. 46. Inversion of Red Sea anomalies at $100 \mathrm{~km}$ depth (to indicate the depth of subbranches).

\subsubsection{Zagros gravity anomalies}

Figs. 47 to 50 show the inversion results. Fig. 47 shows a view from above and Fig. 48 shows another view of Zagros anomalies. According to Fig. 49, the effective depth of this anomaly is about $180 \mathrm{~km}$ and from the depth of $200 \mathrm{~km}$, the anomalous root proceeds incoherently (Fig. 50) and it ends up at an approximate depth of 400 kilometres.

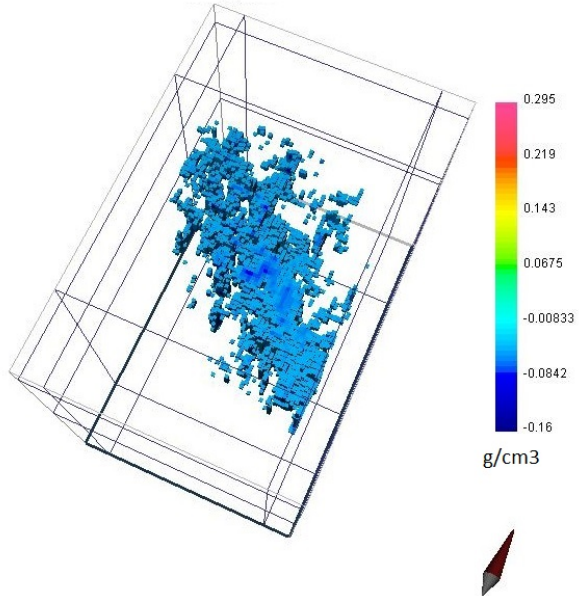

Fig. 47. Inversion of Zagros anomalies (top view).

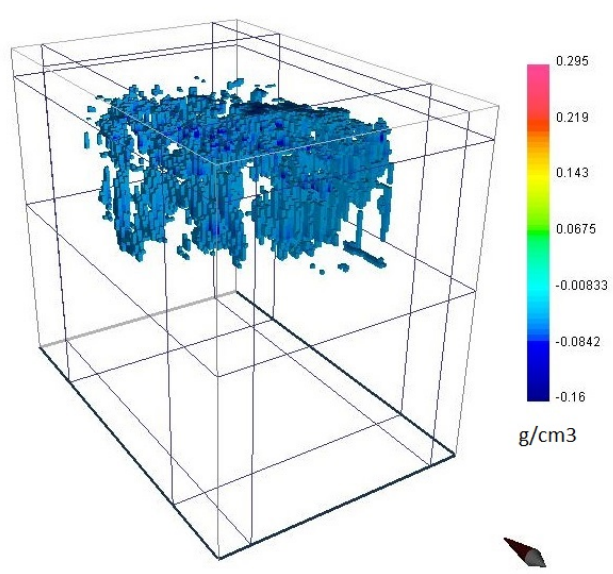

Fig. 48. Another view of Fig. 47. 


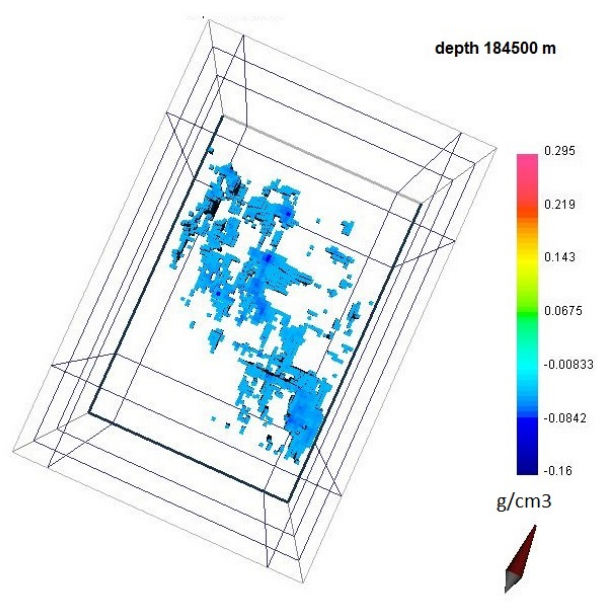

Fig. 49. Inversion at an approximate depth Fig. 50. Inversion at an approximate depth of $184 \mathrm{~km}$.

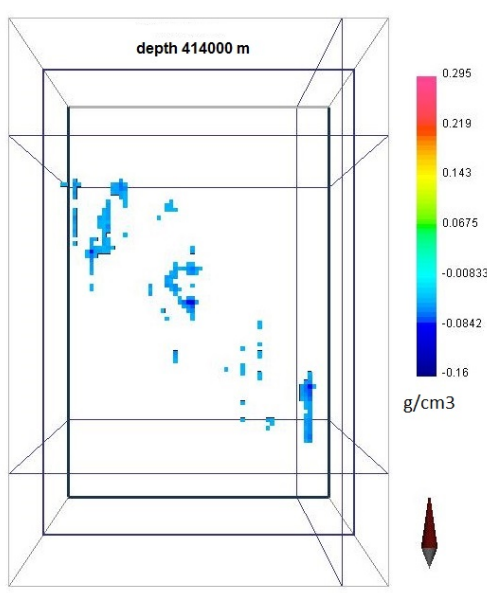

of $414 \mathrm{~km}$.

\section{Conclusion}

In the case of Zagros gravity anomalies, the results of the edge detection filters indicate that the performance of the regularized derivatives with the elimination of the noise from the unregularized filters mode become an improvement in the results. Also these anomalies extend from northwest to southeast with indentations and reliefs. The general trend of this surface is in accordance with the geological trends of the area. The inversion results also show that the effective depth of this anomaly is about $180 \mathrm{~km}$ and after that, the anomalous root proceeds incoherently and it ends up at an approximate depth of 400 kilometres. In the case of anomalies of the Red Sea, applying edge detection filters revealed that this region is more complex than the Zagros region and these anomalies started from the north-western corner and led to many fractures to the centre, then divided into three main branches, which were again interconnected in the southeast corner, there is also a subway to the south for the western branch. These results are in line with the geological features of the Red Sea and the curvature direction and even the western branch path are well shown. Three-dimensional modelling also showed that the effective depth of these anomalies is $200 \mathrm{~km}$ from the surface and eventually end at about $300 \mathrm{~km}$. Also the depth of the two 
branches of this anomaly was lower than its main branch because these two branches continue to a depth of $100 \mathrm{~km}$ and then disappear.

\section{References}

Agah A., Doulati Aredejani F., Moradzadeh A., Tabatabaei Raeisi H., 2004: Integrating aerial and ground magnetic data to identify oil potentials in the Tabas area. 8th Iranian Geological Conference.

Agard P., Omrani J., Jolivet L., Mouthereau F., 2005: Convergence history across Zagros (Iran): constraints from collisional and earlier deformation. Int. J. Earth Sci., (Geologische Rundschau), 94, 3, 401-419, doi : 10.1007/s00531-005-0481-4.

Alavi M., 1994: Tectonics of the Zagros orogenic belt of Iran: New data and interpretations. Tectonophysics, 229, 3-4, 211-238, doi: 10.1016/0040-1951 (94) 90030-2.

Alavi M., 2007: Structures of the Zagros fold-thrust belt in Iran. Am. J. Sci., 307, 9, 1064-1095, doi: 10.2475/09.2007.02.

Allahyari K., Saccani E., Pourmoafi M., Beccaluva L., Masoudi F., 2010: Petrology of mantle peridotites and intrusive mafic rocks from the Kermanshah ophiolitic complex (Zagros belt, Iran): implications for the geodynamic evolution of the neoTethyan oceanic branch between Arabia and Iran. Ofioliti, 35, 2, 71-90.

Ariamanesh M., Mahmoudpour Z., 2012: Survey of hidden faults in Ahar region based on airborne graviy data. National Congress Planning the Pathology and Earthquake Effects. 21 August 2012 in East Azerbaijan Province.

Arısoy M. Ö., Dikmen Ü., 2011: Potensoft: MATLAB-based software for potential field data processing, modeling and mapping. Comput. Geosci., 37, 7, 935-942, doi : $10.1016 / j$. cageo.2011.02.008.

ArRajehi A., McClusky S., Reilinger R., Daoud M., Alchalbi A., Ergintav S., Gomez F., Sholan J., Bou-Rabee F., Ogubazghi G., Haileab B., Fisseha S., Asfaw L., Mahmoud S., Rayan A., Bendik R., Kogan L., 2010: Geodetic constraints on present-day motion of the Arabian Plate: Implications for Red Sea and Gulf of Aden rifting. Tectonics, 29, 3, TC3011, doi: 10.1029/2009TC002482.

Berberian M., 1995: Master "blind" thrust faults hidden under the Zagros folds: active basement tectonics and surface morphotectonics. Tectonophysics, 241, 3-4, 193224, doi: 10.1016/0040-1951(94)00185-C.

Besse S., Rebouillat D., Marie I., Puvion-Dutilleul F., Hovanessian A. G., 1998: Ultrastructural localization of interferon-inducible double-stranded RNA-activated enzymes in human cells. Exp. Cell Res.,239, 2, 379-392, doi: 10.1006/excr.1997. 3908.

Blakely R. J., 1996: Potential theory in gravity and magnetic applications. Cambridge University Press, Revised edition, $464 \mathrm{p}$.

Bosworth W., Huchon P., McClay K., 2005: The Red Sea and Gulf of Aden basins. J. Afr. Earth Sci., 43, 1-3, 334-378, doi: 10.1016/j.jafrearsci.2005.07.020. 
Amjadi A. et al.: Edge detection, depth estimation and 3D-inverse modelling... (1-32)

Camp V. E., Roobol M. J., 1992: Upwelling asthenosphere beneath western Arabia and its regional implications. J. Geophys. Res., 97, B11, 15255-15271, doi: 10.1029/ 92JB00943.

Cooper G. R. J., Cowan D. R., 2006: Enhancing potential field data using filters based on the local phase. Comput. Geosci., 32, 10, 1585-1591, doi: 10.1016/j.cageo. 2006.02 .016 .

Danaei G., Finucane M. M., Lu Y., Singh G. M., Cowan M. J., Paciorek C. J., Lin J. K., Farzadfar F., Khang Y.-H., Stevens G. A., Rao M., Ali M. K., Riley L. M., Robinson C. A., Ezzati M., 2011: National, regional, and global trends in fasting plasma glucose and diabetes prevalence since 1980: systematic analysis of health examination surveys and epidemiological studies with 370 country-years and 2.7 million participants. Lancet, 378, 9785, 31-40, doi: 10.1016/S0140-6736(11)60679-X.

Dehghani G. A., Makris J., 1984: The gravity field and crustal structure of Iran. Neues Jahrb. Geol. Paläontol. - Abhandlungen, 168, 2-3, 215-229, doi: 10.1127/njgpa/ $168 / 1984 / 215$.

Deif A., Al-Shijbi Y., El-Hussain I., Ezzelarab M., Mohamed A. M. E., 2017: Compiling an earthquake catalogue for the Arabian Plate, Western Asia. Journal of Asian Earth Sciences, 147, 345-357, doi: 10.1016/j.jseaes.2017.07.033.

Del Chiaro M., Rangelova E., Halimi A., Ateeb Z., Scandavini C., Valente R., Segersvärd R., Arnelo U., Verbeke C. S., 2019: Pancreatectomy with arterial resection is superior to palliation in patients with borderline resectable or locally advanced pancreatic cancer. HPB, Oxford, 21, 2, 219-225, doi: 10.1016/j.hpb.2018.07.017.

Doulati Ardejani F., 2011: Raw survey data and interpretation of Marvdasht Exploration Area. Master thesis, Amirkabir University, Faculty of Mining, Tehran.

Ebrahimzadeh Ardestani V., 2010: Applied Gravity. In: Mineral Exploration, Engineering Geology. Tehran, Institute of Tehran University.

Falcon N. L., 1969: Problems of the relationship between surface structure and deep displacements illustrated by Zagros range. In: Kent P. E., Satterthwaite G. E., Spencer A. M.: Time and Place in Orogeny. Geol. Soc. Spec. Publ., 3, 9-21, doi: 10.1144/GSL.SP.1969.003.01.02.

Foulger G. R., Pierce C., 2007: Geophysical Methods in Geology. Teaching Handbook, University of Durham, UK, 78 p.

Ghasemi A., Talbot C. J., 2006: A new tectonic scenario for the Sanandaj-Sirjan Zone (Iran). J. Asian Earth Sci., 26, 6, 683-693, doi: 10.1016/j.jseaes.2005.01.003.

Giese P., Makris J., Akashe B., Röwer P., Letz H., Mostaanpour M., 1984: The crustal structure in Southern Iran derived from seismic explosion data. Neues Jahrb. Geol. Paläontol. - Abhandlungen, 168, 2-3, 230-243, doi : 10.1127/njgpa/168/1984/230.

Hadadian A., 2011: Precise boundary detection of potential field anomalies using local phase filters. M.Sc. Thesis, Shahrood University of Technology, $102 \mathrm{p}$.

Hinze W. J., 1990: The role of gravity and magnetic methods in engineering and environmental studies In: Geotechnical an Environmental Geophysics: Volume I: Review and Tutorial. Society of Exploration Geophysicists, 75-126, doi: 10.1190/1.97815 $60802785 . \operatorname{ch} 4$. 
Horton B. K., Hassanzadeh J., Stockli D. F., Axen G. J., Gillis R. J., Guest B., Amini A., Fakhari M. D, Zamanzadeh S. M., Grove M., 2008: Detrital zircon provenance of Neoproterozoic to Cenozoic deposits in Iran: Implications for chronostratigraphy and collisional tectonics. Tectonophysics, 451, 1-4, 97-122, doi : 10.1016/j.tecto. 2007.11 .063$.

Jafarzadeh V., 2015: Three-dimensional inverse modeling of gravity data using the LiOldenburg method (Case study: Sabzevar region). Master thesis. Shahrood University of Technology.

Kolagari A. A., 1992: Principles of geophysical exploration, Radish Publishing, 585 p.

Li Y., Oldenburg D. W., 1998: 3-D inversion of gravity data. Geophysics, 63, 1, 109-119, doi : $10.1190 / 1.1444302$.

Madahizadeh R., Mostafazadeh M., Ashkpour-Motlagh S. H., 2016: Earthquake Potential in the Zagros region (Iran), Acta Geophysica, De Gruyter, 64, 5, 1462-1494, doi : $10.1515 /$ acgeo-2016-0080.

Makris J., Rihm R., 1991: Shear-controlled evolution of the Red Sea: pull apart model. Tectonophysics, 198, 2-4, 441-466, doi: 10.1016/0040-1951(91) 90166-P.

Miller H. G., Singh V., 1994: Potential field tilt-a new concept for location of potential field sources. J. Appl. Geophys., 32, 2-3, 213-217, doi : 10.1016/0926-9851(94) 90 022-1.

Morcos S. A., 1970: Physical and chemical oceanography of the Red Sea. Oceanogr. Mar. Biol. Ann. Rev., 8, 73-202.

Nabighian M. N., 1972: The analytic signal of two-dimensional magnetic bodies with polygonal cross-section: Its properties and use for automated anomaly interpretation. Geophysics, 37, 3, 507-517, doi: 10.1190/1.1440276.

Nowroozi A. A., 1971: Seismotectonics of the Persian plateau, eastern Turkey, Caucasus and Hindu-Kush regions. Bull. Seismol. Soc. Am., 61, 2, 317-341.

Pašteka R., Richter F. P., Karcol R., Brazda K., Hajach M., 2009: Regularized derivatives of potential fields and their role in semi-automated interpretation methods. Geophys. Prospect., 57, 4, 507-516, doi: 10.1111/j.1365-2478.2008.00780.x.

Paterson N. R., Reeves C. V., 1985: Applications of Gravity and Magnetic Surveys: The State-of-the-Art in 1985. Geophysics, 50, 12, 2558-2594, doi: 10.1190/1.1441884.

Phillips N., 2001: Geophysical inversion in an integrated exploration program: examples from the San Nicolás deposit. University of British Columbia. Vancouver, Canada: Master's Thesis.

Rasul N. M. A., Stewart I. C. F., 2015: The Red sea. The Formation, Morphology, Oceanography and Environment of a Young Ocean Basin. Springer Earth System Sciences.

Reilinger R., McClusky S., ArRajehi A., 2015: Geodetic Constraints on the Geodynamic Evolution of the Red Sea. In: Rasul N., Stewart I. (Eds.): The Red Sea. Springer Earth System Sciences, Springer, Berlin, Heidelberg, 135-149, doi: 10.1007/978-3 -662-45201-1_7.

Reynolds J. M., 1997: An introduction to applied and environmental geophysics. John Wiley and Sons. 
Amjadi A. et al.: Edge detection, depth estimation and 3D-inverse modelling ... (1-32)

Saccani E., Allahyari K., Beccaluva L., Bianchini G., 2013: Geochemistry and petrology of the Kermanshah ophiolites (Iran): Implication for the interaction between passive rifting, oceanic accretion, and OIB-type components in the Southern Neo-Tethys Ocean. Gondwana Res., 24, 1, 392-411, doi : 10.1016/j.gr.2012.10.009.

Sella G. F., Dixon T. H., Mao A., 2002: REVEL: A model for Recent plate velocities from space geodesy, J. Geophys. Res., 107, B4, 2081, doi : 10.1029/2000JB000033.

Snyder D. B., Barazangi M., 1986: Deep crustal structure and flexure of the Arabian Plate beneath the Zagros collisional mountain belt as inferred from gravity observations. Tectonics, 5, 3, 361-373, doi: 10.1029/TC005i003p00361.

Stern R. J., Johnson P. R., 2010: Continental lithosphere of the Arabian Plate: A geologic, petrologic, and geophysical synthesis. Earth Sci. Rev., 101, 1, 29-67, doi: 10.1016/ j. earscirev. 2010.01.002.

Sultan M., Becker R., Arvidson R. E., Shore P., Stern R. J., El Alfy Z., Attia R. I., 1993: New constraints on Red Sea rifting from correlations of Arabian and Nubian Neoproterozoic outcrops. Tectonics, 12, 6, 1303-1319, doi: 10.1029/93TC00819.

Swartz D. H., Arden D. D., 1960: Geologic history of the Red Sea area. AAPG Bull., 44, 10, 1621-1637.

Verduzco B., Fairhead J. D., Green C. M., MacKenzie C., 2004: New insights into magnetic derivatives for structural mapping. Lead. Edge, 23, 2, 116-119, doi : 10.1190/ 1.1651454 .

Walpersdorf A., Hatzfeld D., Nankal H., Tavakoli F., Nilforoushan F., Tatar M., Vernant P., Chéry J., Masson F., 2006: Difference in the GPS deformation pattern of North and Central Zagros (Iran). Geophys. J. Int., 167, 3, 1077-1088, doi: 10.1111/ j . 1365-246X . 2006.03147.x.

Williams N. C., 2008: Geologically-constrained UBC-GIF gravity and magnetic inversions with examples from the Agnew-Wiluna greenstone belt, Western Australia. University of British Columbia, Vancouver, Canada, Ph.D. Thesis. 